\title{
The learning effects of using infant simulators in Family Life Education: A study of undergraduate students in
} Taiwan

\section{Jang, Li-Fen}

Tzu-Chi University, Taiwan (lifen76209@mail.tcu.edu.tw)

Lin, Yi-Man

Chang Gung University of Science and Technology, Taiwan (marialin@gw.cgust.edu.tw)

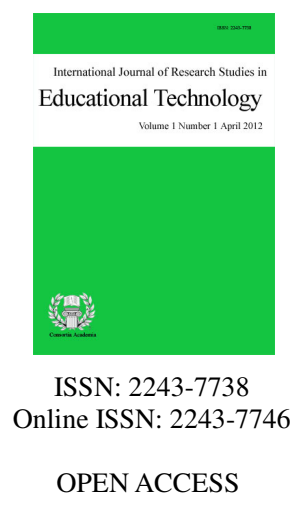

Received: 2 December 2016

Revised: 20 January 2017

Available Online: 12 April 2017 DOI: $10.5861 /$ ijrset.2017.1703

Accepted: 3 April 2017

\section{Abstract}

The purpose of this study explored the perceptions of undergraduate students who employed simulator infants in Family Life Education. All of the participants $(\mathrm{N}=156)$ were undergraduate students majoring in Family Studies programs in Taiwan. The data collection included quantitative reports of proper care scores, questionnaire, and qualitative data from focus group interviews and students' reflective journals. The results showed that participants realized the responsibilities, challenges and difficulties of caring for babies. They had more discussion and open communication with significant others. Infant simulators could be used in Family Life Education in undergraduate courses, and to provide the opportunity for students at the emerging adulthood to think about the consequences of unwanted pregnancy, commitment of parents, preparedness for being parents, and learning child care skills. The implications of the study indicated that infant simulators may be used in the stage of emerging adulthood and provided for faculty and develop curriculum and multiple teaching strategies in Family Studies.

Keywords: infant simulators; technology integrated instruction and learning; family life education; Taiwan 


\section{The learning effects of using infant simulators in Family Life Education: A study of undergraduate students in Taiwan}

\section{Introduction}

Infant simulators have been employed in many sexuality programs for adolescents in United States. The infant simulator is an extraordinary and technologically-advanced model with varied ethnic characteristics that is 21 inches long and weighs 6.5 pounds to 7 pounds. The participants had to feed, burp, rock, and change baby's diaper. These tasks allowed the students to temporarily experience the amount of care and infants' needs, and understand the long-term consequence of early sexual activity and teen pregnancy. Prior research on the infant simulators had been proved that the simulators can be effective devices for adolescents to experience parenthood, child care skills or knowledge, and understand students' attitudes or beliefs regarding pregnancy, and postpone sexual activity. Unfortunately, the use of reality-based simulators has been limited in Taiwan. Few of the simulators have been used in medical courses or nursing programs, and they are rarely used in the undergraduate level of Family Science fields.

During the past 20 years, the studies of infant simulators have extended their associated curriculum to consist of not only courses on pregnancy prevention, but also courses in parenting and child development, and courses for students interested in careers in childcare (Brinkman, Johnson, Codde, Hart, Straton, Mittinty, \& Silburn, 2016). Many studies showed that simulation contributed to the students' learning in multiple professional fields, like, medical (Beth, Cunningham, \& McIntosh, 2000), health care(Johannesson, Silén, Kvist, \& Hult, 2013), and science learning (Sauter, Uttal, Rapp, Downing, \& Jona, 2013). Undergraduate students in Taiwan have seldom hand-on experiences and skills in taking care of babies. Therefore, simulation, such as: simulator babies are used in higher education as an approach to improve teaching and learning. Simulator device is a new way of skill training used to foster practical application of academic training. In addition, simulation is a pedagogical approach to strengthen students' practical skills to become professional.

Moreover, from the life-span perspective, undergraduate students are at the stages characterized by what Erikson termed as identity versus identity confusion stage. Erikson regarded young adulthood as the time of intimacy versus isolation stage. From the sociological perspective, adolescents and young adults experience multiple role transitions, such as finishing education, entering into employment, marriage, and parenthood. Compared with contemporary youth, adolescents of the past make school- and work-related transitions earlier. Adolescents in the modern society confronted more complex issues during this life-span stage; therefore, there is a transition stage between adolescence and adulthood which is called emerging adulthood. According to Arnett (2000), emerging adulthood is proposed as a new conception of development for the period from late teens through twenties, with a focus on ages 18-25. During the college years, the undergraduate students go through their shifting into the emerging adulthood. Moreover, emerging adulthood is the period of life that offers opportunity for identity explorations in the area of love, work, and worldview. Emerging adulthood is considered as culturally constructed. For example, more and more 18-to 25-year-olds spend more time in college (Mortimer, Zimmer-Gembeck, Holmes, \& Shanahan, 2002). Many adolescents in Taiwan chose to attend colleges to obtain their higher education at this age. University is not only the place for education, but also for exploration of their identity, tasks of theirs life. Undergraduate students in the emerging adulthood are still at time of significant change and development on all levels, such as psychological, social and biological development. Therefore, entering college allowed students to explore their identities, such as job, commitment of career, sexual identity, love, and marriage in multiple ways.

According to Arnett (2000), emerging adulthood is a period of feeling "in between". Along with all these changes emerging adulthood are faced with situations in which they must make important choices and decisions, such as: role transitions, school, job, marriage, and parenthood. Therefore, Infant simulators were used as the 
device to explore the real life events or the opportunities of role play, such as pregnancy, parenthood, and child care skills. Infant simulators were used in the Family Life Education at undergraduate level and provided the opportunity for students at the emerging adulthood to think about the consequences of unwanted pregnancy, commitment of parents, preparedness for being parents, and awareness of child care skills. Infant simulators were served as tools/kits that allowed students to practice and prepare for real-life events during their collage years.

\subsection{Research Questions}

The purpose of this study was to investigate-the undergraduate students' attitudes towards parenthood and taking care of infants, and whether their experiences changed their personal perceptions of child care after taking care of simulator babies. For the purpose of this study, the objectives were to obtain answers to following questions:

$>$ Do the students change their attitudes and beliefs after caring for an infant simulator?

$>\quad$ What do the students learn from experiencing an infant simulator?

\subsection{Significance of the study}

It is essential to use technology devices as teaching approach in teaching real-life event, opening discussion with students, and the simulator is a great resource in teaching Family Life Education, or Family and Marriage, Parent Education in the undergraduate level. This study was to allow the students in utilizing infant simulators to temporarily experience the amount of care and infants' needs, skills of caring babies, and understand the long-term consequence of unplanned pregnancy.

\section{Literature Review}

David Kolb's conception of experiential learning was used as the framework in this study. Learning is the process whereby knowledge is created through the transformation of experiences (Kolb, 1984). According to Kolb, the process of experiential learning can be described as a four-stage cycle. The four stages included concrete experience, reflective observation, abstract conceptualization, and active experimentation. The concrete experiences were based on real life experiences. By participating in real-life activities, students are able to efficiently obtain hand-on experiences. Based on these hand-on experiences, students are able to transform the knowledge and experiences from taking care of simulator babies into their understandings. For instance, the infant simulators in this study provided understandings such as parenting skills, responsibilities, demands, and frustrations of parenting by experiential learning. The students may apply these knowledge in the real world in the future.

Baby simulators have been used in previous studies in the States, especially in adolescents and pre-adolescents. Strachan and Gorey (1997) compared two groups with and without using baby simulators. The majority of the participants who joined the programs scored higher on a measure of realistic parenting expectation. The infant simulator provided a realistic experience for adolescents and help students realized their attitudes and beliefs about what their future parenting experiences might be like. In addition, the caring experiences help adolescents acquired concrete experiences, such as parenting skills. Furthermore, adolescents were allowed to extend their understanding to form abstract conceptions. For example, the influence of unplanned pregnancy might impact their life. Early childbearing may influence their educational attainment, and research showed that educational attainment was highly correlated with the age at first birth (Diez \& Mistry, 2010). Therefore, prevention of unplanned pregnancy is important for adolescent to reduce the percentage of teens dropping out of school.

Price, Robinson, Thompson, and Schmalzried (2000) had investigated parents whose adolescent children 
experienced 3-day Baby-Think-It-Over (BTIO) program. Parents perceived that BTIO programs taught their children that having a baby involves a lot of responsibility, is time consuming, and keeps them from meeting their goal in life. In addition, parents indicated the program increased their parent-child communication about sexuality and parenting issues, such as the consequences of having a baby, sex, or being a parent.

Previous research showed simulated infants could be prevented to unplanned teen pregnancy, and to foster attitudes toward parenting, as well as the ability to provide competent child care skills (Roberts \& McCowan, 2004). Results from these studies showed that the infant simulator can have a positive effect on the attitudes and knowledge of adolescents about pregnancy and childrearing (McCowan, Roberts, \& Slaughter, 2009). Tingle (2002) investigated 25 teachers, 431 students and 299 parents about their perspectives regarding using infant simulators. From the parents' point of view, $30 \%$ of parents believed that infant simulator had positive effects, and increased communications for adolescents and parents to engage in sexual education and parenting. The results from teachers' perspectives showed that $23 \%$ of the participants indicated BTIO as very effective-to prevent pregnancy, and $27 \%$ indicating BTIO as very effective to change the attitudes of high-risk pregnancy. Parents' and teachers' perspectives indicated that this activity increased the communications for adolescents and parents to engage in sexual education and parenting. However, results from students did not support the same outcomes, beliefs and perceptions of parenthood after the intervention were minimal. There were no significant change in attitudes and beliefs about parenting.

Beth, Cunningham, and McIntosh (2000) employed infant simulators for medical students to investigate whether they changed their attitudes regarding parenting. Simulated babies are of limited values for medical students in increasing their parental concerns, and the participants indicated that they did not count the caring experiences as useful or realistic. However, they felt the burden to be more physical than mental. While, Divine and Cobbs (2001) used infant simulators as part of the health and sex education curriculum, and examined 236 students regarding issues related to infant care, having children, and sexual behaviors. The results indicate students realized responsibilities, postponed having children in their teen years, and learned to meet the challenges of infant care. In consideration of gender differences, the results showed the doll experiences had a significant impact on the female students, such as understanding the possible implication before engaging in sexual intercourses.

Malinowski and Stamler (2003) employed the phenomenological approach to gain the perspectives about parenting a newborn from adolescents. The participants cared for the baby simulators for 7 days during a parenting course. The participants in this study realized the difficulties in integrating the babies into their weekday responsibilities, such as doing homework, housework, and some leisure time in weekend. In addition, the experiences were realistic for the participants, for example, they have experienced sleep disruption. Also, Didion and Gatzke (2004) employed survey and focus group for 11th Grade students regarding their attitudes, actual and intended sexual practices, feelings and opinions after caring the babies. The results of this study showed the participants realized the consequences of pregnancy and teen parenthood to be negative, and reported that they intended to delay childbearing. In addition, the participants mentioned about confronting sleep deprivation and the loss of freedom in their lives, and some of them faced embarrassed experiences, such as social disapproval, because someone would think these adolescents were carrying a real baby. The BTIO program increased the chances for adolescents and parents to engage in sexual education and discussion in a spontaneous way.

Although several studies supported that infant simulators changed adolescents' perceptions regarding unplanned pregnancy and parental roles after caring for the babies, the results of these studies suggest that the effectiveness of using infant simulators to influence the perceptions of teens about the reality of teen parenting is minimal (Herrman, Waterhouse, \& Chiquoin, 2011; Out \& Lafreniere, 2001). Several studies have yielded little evidences to support the use of infant simulators. Moreover, Barnett (2006) found students with and without BTIO experiences showed no significant differences in these measures, such as, communication with parents, attitudes toward teen sex, knowledge about sex, and sex behaviors. In a Western Australia study, the researchers 
indicated that using simulator baby didn't result in reducing teen pregnancy, however, the study of the results need to be considered, such as a higher pregnancy risks in girls who were in intervention groups (Brinkman et al., 2016).

Barnett and Hurst (2004) investigated 227 eighth and tenth graders students. The results indicated that female and younger groups were taken seriously in caring of infant simulators. The participants reported knowing the difficulties of caring for infant, and helping students to think about possible implication before engaging in sexual behavior, and in addition, they reported understanding the importance of delaying parenthood. Furthermore, Lou and Chen (2008) investigated 823 junior college students in Taiwan, and the result of the findings demonstrated that sexual knowledge has no direct effect on safe sex behavior, and sexual knowledge has a significant direct negative effect on sexual attitudes. Adolescences have more sexual knowledge, both their bodies and health statuses are in emotionally and physically changing process at this point in their life. It is the time when the majority of adolescents tend to see themselves at the center of everything, for example, like adolescent egocentrism and personal fable (Elkind, 1967). What would be the effective methods to prevent unplanned pregnancy in cognitive and behavior ways? Baby simulators provided a way for adolescents to understand the consequences of unplanned pregnancy. However, these remained a lot of efforts to avoid sexual behaviors and unwanted pregnancy.

\section{Methods}

\subsection{Participants}

All the participants volunteered for a 48-hour period which they cared for an infant simulator. All of the participants $(N=156)$ were undergraduate students majoring in Family Studies programs in Taiwan. 28 participants were male and 128 were female. The 18-22 year-old participants did not have their own children and had little experience caring for newborn babies ( $M=19.0$ years old). Most of the participants did not live with their families, $92.3 \%$ of the participants live in the dormitory. In addition, 5.8\% of them live with families, and $1.9 \%$ were out of campus. In this study, the majority of the participants were freshmen $(N=134), 13$ of them were sophomore; 2 was junior, and 7of the participants were senior students. In this study, the participants were allowed to work in pairs, or work alone as a single parent. Students are able to arrange helper as babysitter; however, the quantitative scores of helpers were counted as their assignment points. In addition, participants need to take responsibility for their babysitters.

\subsection{Procedures}

All of the participants attended the 60-minute personal instruction before experiencing the infant simulator. It included demonstration, and practiced of all of the activities, such as feeding, burping, rocking and diaper changing, and fussy modes. The student should respond to the baby's situations and provided proper care until the baby stops crying. In addition, the researcher presented the skills of head support, and techniques which avoid rough handle, and wrong position. A questionnaire was developed by the researcher for the study. All of the participants filled up the questionnaire at the end of the care period. The first section was demographic questions which investigated their gender, age, year/category, living in campus or not. The second section of the instrument consisted of 11-questions which investigated participants' the perceptions about-parenthood, and unplanned pregnancy. Content and face validity were established by three professors of child development and family studies, and 3 students who participated in pilot study of this activity.

\subsection{Data Collection}

The data collection included quantitative reports of proper care scores, questionnaire, and qualitative data from focus group interviews and students' reflective journals were included as well. In addition, the quantitative reports of proper care were retrieved from the infant simulator. The report recorded how many times the 
simulated baby was responded to, such as feeding, burping, rocking, fussy, and diaper changing. In addition, the device documented how many times the simulated baby was mishandled or miscared, for example, wrong position, rough handling, improper head support, and shaken baby. All participants were asked to fill in questionnaires, and 28 of participants were voluntary to participate in two focus groups, and the participants were able to exchange their perspectives about caring for babies, attitudes, knowledge and beliefs of being parents. The co-researchers collected the data from focus groups interviews, and both of the focus group interviews were audio taped to ensure accuracy.

\subsection{Data Analysis}

Frequencies and percentages were used to analyze ordinal and nominal data. Mean and standard deviation were calculated for investigating their perceptions regarding caring experiences. Independent t-test was used to examine gender differences on proper care scores. Qualitative data were gathered through the focus groups and reflective journals. The audio of all focus-group interactions was tape recorded and transcribed. The purpose of audio-taping was for translating the data accurately from Chinese into English and for verification of the transcript by a second translator. The data from focus groups, and reflective journals were grouped by identifying recurrent themes contained in the text of all focus group transcripts. The process of generating themes was categorized into six steps: familiarization with the data, generating primary codes, exploring for themes, reviewing and refining themes, defining and identifying themes, and constructing reports (Braun \& Clarke, 2006).

\section{Results}

After finishing the activity, the researchers retrieved the quantitative data as proper care scores from the infant simulator. Each participant was required to submit their questionnaire as well as their reflective journal and was invited to join focus group for sharing their ideas.

\subsection{Attitudes and Beliefs}

The 4-point Likert-scale ranged from 4 (strongly agree) to 1 (strongly disagree). Reliability coefficients were 0.61 . The greater the mean value, the more agreement was for their perceptions and attitudes of parenting, and unplanned pregnancy. With respect to the perceptions of parenting, childrearing, results indicated that participants agreed with these items. This activity made me realize the responsibilities of being a parent $(M=3.75)$. This activity made me realize how easy it is to hurt a baby $(M=3.73)$. Most participants agreed that unplanned pregnancy would impact their personal plan $(M=3.59)$. On the other hand, most participants did not agree that they were ready to be a parent after this activity $(M=2.42)$. The result has shown on Table 1 .

\section{Table 1}

Attitudes and Beliefs of Caring for Infant Simulators $(N=156)$

\begin{tabular}{lcc}
\multicolumn{1}{c}{ Items } & Mean & SD \\
\hline This activity made me want to become a parent. & 2.87 & .86 \\
This activity made me realize how easy it is to hurt a baby. & 3.73 & .45 \\
This activity helped me learn the skills of caring for babies. & 3.48 & .56 \\
This activity made me realize how much fun babies are. & 3.25 & .85 \\
This activity made me realize I am ready to become a parent. & 2.42 & .91 \\
This activity helped me decide to postpone having a child. & 2.71 & .93 \\
This activity showed me how it would be a single parent. & 3.30 & .74 \\
This activity made me realize the responsibilities about parenthood. & 3.75 & .44 \\
This activity made me realize unplanned pregnancy could impact my personal plan. & 3.59 & .64 \\
This activity made me think it could take care of a child on my own. & 3.51 & .57 \\
This activity made me understand how hard to negotiate housework. & 3.50 & .62 \\
\hline
\end{tabular}


When the simulation was ended, the data from the simulator was exported. Proper care score based on the percent of time that the participants responded to babies properly, including rocking, diapering, burping and feeding. The mean scores of proper care were 94.18, SD=6.67, and the highest scores were 100, and 64 were the lowest score. However, three participants were recorded as abuse stop. It meant the baby was abused at least 24 times and the simulation was shut down in order to protect the device. Proper care score also recorded the time of mishandle situations, such as wrong position, rough handling, without head support and shaken baby. The mean score of female students were 93.48, $\mathrm{SD}=7.27$, and the mean score of male students were 96.68, $\mathrm{SD}=3.98$. Independent t-test revealed no differences in proper care scores in participants' gender $(F=3.11, p>.05)$. There were no significant differences in scores between male and females students.

\subsection{What did the participants learn?}

By writing reflective journals and attending focus groups, students were allowed to think and talk about their perceptions regarding pregnancy, commitment of being parents, and skills of taking care of babies. The data from reflective journals and focus groups were employed to understand the perceptions of participants. After students participated in these activities, the experiences and reflections can influence their reaction to similar events in the future, and moreover, the experience affected their decision-making regarding their attitudes of being parents, and parenting as teenagers.

The present study provided opportunities for participants to experience being parents during the care periods. Qualitative data of focus groups interviews were collected by co-researchers, and the participants expressed their perceptions regarding their experiences. Most undergraduate students reported the simulator baby was an excellent learning experience. Themes were organized in the following categories:

Challenge and Responsibilities - Focus group participants described the challenges and responsibilities that they have to deal with during the caring periods.

"I understood taking care of real babies were more complicated and difficult than taking care of simulators. Taking care of babies were a heavy burden and huge challenge."

"Raising a baby costs a lot of money and energy; I realized that I can't afford so much money now. The couples need to discuss it together before pregnancy."

"It costs a lot to raise a real baby; for example, diaper and milk. As a student, I can't afford it."

"Before this activity, I like children because they are so cute; however, I realized I can't take responsibility for being a mother. I decide not to have a child in the future."

"I appreciated this opportunity and lesson for caring a baby. I have learned to be patient with my baby, because it took time to feed a baby. Therefore, I have to think about to improve my efficiency."

One participant mentioned that finding a nanny was important, and this activity made her had more motivation to gain knowledge of child care policies and regulations.

During the periods, I need to ask my friends to act as nannies, and it's important to find a reliable person to take care of my baby. Therefore, I believed regulations for day care centers are necessary. I would like to understand more of the policies regarding these issues.

The activity provided open communication opportunities for students and parents, and some of the participants mentioned the family communication, and the opportunities for discussion regarding caring for the baby, unplanned pregnancy, and an appreciation to their parents.

Policies - Participants pointed out about the importance of policy, such as related to education, or family 
Jang, L.-F., \& Lin, Y.-M.

friendly public policies.

"From this activity, I realized the importance of the quality of the baby-sitter; therefore, providing the good daycare centers, or teaching parents in finding good baby-sitters is important".

In addition, a participant mentioned that she realized that more multiple-purpose restrooms for males and females are necessary, such as family restroom or providing more space for baby changing stations in public areas.

Social Opinions - Some of participants also mentioned the issue of social disapproval. They feel embarrassed when they hold a baby in public or in a crowd, and they just wondered how the bystanders thought about them, such as, "you are too young to have a baby." Due to the conservative environments of Taiwan society, young students felt under the stress from others judgments.

"Those older parents taught me how to hold the babies or shared their experiences with me" On the other hand, some participants described positive experiences. For example, when they hold a baby in public, some persons felt curious about the assignment, and would like to know the details about the simulator baby, and some bystanders shared the caring experiences with participants, even though they eventually knew the participants were not real parents.

Change of Perspectives - From two focus groups with undergraduate students, we have identified some beliefs and attitudes about being a parent in the future. "Before the activity, I think it's ok to be a single mom; however, I changed my idea now. It's better to have a partner to raise a child together". The activity also provided the chances for them to think about their current life, such as: school, future careers, or the impacts of unplanned pregnancy. "I preferred delaying to have a baby; I don't want to change my life style now".

Open communication with significant others - Due to the activity, several participants mentioned that they have open communication with parents or boyfriends. The participants may seek some advices of caring for babies, or expressed their appreciations to parents

"I called my mother, and asked her some questions about holding a baby without hurting his neck, sharing my reflection to my parents."

"I called my parents to express my appreciation. After taking care for the baby, I realized how difficult it was, and my parents spent time and money for caring for me."

"This activity provides me to have the discussion with my boyfriend, such as, whether having a child in the future, how to arrange housework while we were taking care for the baby. I found my boyfriend enjoys being a father."

Loss of personal freedom - Some participants mentioned loss of freedom, such as sleep deprivation, loss of time for their social life, and opportunities for attending daily activities. For instances, "I have to quit playing online games with my friends" Changing their daily schedules of sleep deprived.

"I have to feed the baby, and I can't sleep well during the night."

In conclusion, participants gained experiences from those caring activities. They extended their points of view, obtained real experiences, and understood the responsibilities, challenges and difficulties from the simulated babies. In addition, the participants also learned the different perceptions of parenthood.

\section{Discussion and Implications}

The aim of this study was to examine whether an experiential approach to family life education, infant 
simulator, was effective in changing emergent adults' attitudes toward and perceptions of parenting, as well as actual behaviors that are linked to understanding the consequences of unplanned pregnancy. After caring for the infant simulator, high school students had significantly more realistic attitudes to parenting and to dealing with a persistently crying infant (Roberts \& McCowan, 2004; Strachan \& Gorey, 1997). In this study, the participants agreed that they learned the responsibilities of being a parent $(M=3.75)$, such as respond to baby's needs immediately, and providing secure environment to protect their fragile babies. In addition, the results showed they realized it was not easy to care for an infant, and by finishing the activities, they knew the skills of caring for the baby, and understanding the impacts of unplanned pregnancy. The qualitative results showed that participants realized the challenges and difficulties when caring for an infant. They needed more skills and preparation to become parents.

In the focus groups, the participants indicated that this activity opened up communication with their parents, such as parenting, and the attitudes about being parents. The finding consisted with the previous findings (Didion \& Gatzke, 2004; Price et al., 2000; Tingle, 2002). However, compared with Western cultures, Taiwanese parents provided fewer opportunities with children regarding sexual attitudes during the activities of experiencing the infant simulators. In this study, parents in Taiwan actively provided child care information or skills for their children while their undergraduate children were experiencing the simulators; however, parents seldom discussed sexual or intimacy issues with children of emerging adulthood. It is possible that parents in Taiwan were more conservative than parents in Western society.

On the other hand, taking care of infant simulators open communications between participants and their boyfriend, and they were able to discuss the related issues, like having a baby or not in the future, and consequences of unwanted pregnancy. Compared with previous studies, adolescent participants mentioned open communications with parents; however, undergraduate students mentioned they open discussion with an intimate partner. In previous studies, the finding of simulator's experiences supported having family outcomes (Didion \& Gatzke, 2004), such as parent involvement, parent-child discussion. In this study, infant simulators provided positive outcomes from parent-children interactions, for example, participants mentioned the experiences brought opportunities for engaging in discussion in a spontaneous way. The participants discussed the baby's situations or caring skills with parents, and showed their appreciation for parents. Ultimately they realized being a parent is not an easy task. In addition, the participants mentioned they realized taking care of babies was difficult, and they called their parents to express appreciation.

Most of the participants showed the higher scores on the proper cares. Proper scores were recorded as the parental attitudes, and Independent $t$-test revealed no significant difference between female and male students. The assignment was the part of voluntary activity, and students were able to choose to join or not. The participants were voluntary to choose and the major of participants are Child Development and Family Studies, and they may be more interested in caring for children than other majors. Borr (2009) pointed out infant simulators were viewed as an experiment or a safe way for adolescents to experience parenting. The results of the study were consistent with Malinowski and Stamler (2003). The real experiences of caring for simulators helped participants realize that they were not ready to be parents. The participants started thinking more seriously about the consequences of unwanted pregnancy and impacts on their life. Roberts and McCowan (2004) reported that participants were able to understand the importance of delaying parenthood after caring for the infant simulator. Consistent with the literature, the participants in Taiwan also indicated that the activity helped them decide to postpone having a child.

In this study, students were allowed to find a nanny as helper. When it comes to dual income married couples, many couples should consider looking for a good nanny for taking care of their children. In this activity, students mentioned finding a responsible nanny was so important when they were not available to take care of children. As all of the participants major in Child Development and Family Studies, the activity also linked to their selections of future careers, especially in family education, parenting education or working with infants and toddlers. 


\subsection{Limitation}

The activities were designed for the class of Family Life Education at under-graduate level, and the participants were voluntary to participate in this activity. In addition, these participants major in related areas, such as Family Studies, or Child Development. Thus, one should be cautions in generalization of the results.

\subsection{Implications}

There were several implications for students, family life educators, researchers and faculty. From previous research, many studies focused on how to use infant simulators as tools or assistant devices for preventing adolescent unplanned pregnancy, or used in sexuality programs to teach adolescent students' sexual attitudes, or knowledge of child care. In Taiwan, the infant simulators are seldom used in the sexual education or experimental courses. In this study, infant simulators were used in the class of Family Life Education at the undergraduate level. The participants of the study fall into the period of emerging adulthood rather than adolescence, and the three-day activity provided the opportunities to use this device for experiencing parenthood, and thinking about the consequences of unplanned pregnancy, parenthood, and discussing these issues with parents, teachers and peers. Throughout the experimental activity, many participants realized that they were not ready to take responsibility for being parents, lacking in financial, social, psychological, and emotional preparedness. However, the students were able to experience the difficulties of child care skills, and to understand time management. These experiencing activities may extend to the students in the emerging adulthood. In addition, the stimulators may be used for family science practitioners in teaching Family Life Education, such as the areas of Parenting Education, Child care or Child Development for parents of newborn.

There is also implication for faculty and curriculum design. In this study, the participants majored in Family Study and Child Development. The activity helped students in Family Study major to understand the contents of Family Life Education, such as parent education, child care skills, gender education, and labor in the family. It also provided the positive evidences for using technology device in Family Science courses, such as Family Life Education or Parenting Education. Even though the activity was designed for taking care of babies, some students provide their reflections regarding governmental policies, such as gender equality, evaluation systems for day care centers or baby sitters, and family friendly policies. These experiences offered the students opportunities to think about governmental policies, especially for those who major in Family Studies or Early Childhood Education. The infant simulators enlighten students in Family Studies regarding the responsibilities of parenthood, and family professional which link to their future career as well. It also provides the possibilities for integrating technology, like infant simulators into undergraduate-level courses, and extends the usage to different teaching approaches, like Family Studies or Parenting Education.

Due to the educational opportunities and job markets, the median age of first marriage was postponed for young adults in Taiwan. According to the Ministry of the Interior (2013), the median age for a man's first marriage in Taiwan was 31.9 years in 2012, up from 31 in 1992. The median age for a woman's first marriage was 29.5 years in 2012, up from 26.8 in 1992. During this period of emerging adulthood into early 30 s focus on developing close, intimate relationships with others. Compared with the period of adolescents, exploration in love in emerging adulthood tend to explore the potential for emotional and physical intimacy, and are more likely to include sexual intercourse, or may include cohabitation. On the other hand, using the technology devices as the experimental learning tools helped students in understanding the contents of the curriculum. During the emerging adulthood, students' cognitive strategies tend to be concrete, rather than abstract. It is essential to use technology devices in bringing real-life event, and technology device, like the infant simulator, is a better resource in teaching Family Life Education, or Family and Marriage course in the undergraduate level. It can be used designing in the curriculum for the undergraduate at the emerging adulthood for exploring their attitudes of marriage, and parenthood. 


\section{Conclusion}

This study indicated that infant simulators could be not only be a part of teaching strategies in Family Life Education at undergraduate level, but also help students experiencing a real life event at emerging adulthood. The study integrated technology into the course of Family Life Education, and by participating in the projects; the students are allowed to reflect upon their perceptions about their attitudes and beliefs of being parents. Not like United States, Family Studies Courses at undergraduate level is still a new and professional field. The present study highlights the different strategies in teaching Family Life Education, and it helped students who do not have real caring experiences obtain more concrete experiences.

\section{References}

Arnett, J. J. (2000). Emerging adulthood: A theory of development from the late teens through the twenties. American Psychologist, 55(5), 469-480. https://doi.org/10.1037/0003-066X.55.5.469

Barnett, J. E (2006). Evaluating "baby think it over" infant simulators: A comparison group study. Adolescence, 4l(161), 103-110.

Beth, L. E., Cunningham, S., \& McIntosh, N. (2000). Medical students' attitudes to caring for a young infant-Can parenting a doll influence these beliefs? Archives of Diseases in Childhood, 83(6), 521-523. https://doi.org/10.1136/adc.83.6.521

Borr, M. L. (2009). Baby think it over: A weekend with an infant simulator. Journal of Family \& Consumer Sciences Education, 27(2), 45-55.

Braun, V., \& Clarke, V. (2006). Using thematic analysis in psychology. Qualitative research in psychology, 3(2), 77-101. https://doi.org/10.1191/1478088706qp063oa

Brinkman, S. A., Johnson, S. E., Codde, J. P., Hart, M. B., Straton, J.A., Mittinty, M. N., \& Silburn, R. (2016). Efficacy of infant simulator programmes to prevent teenage pregnancy: A school-based cluster randomised controlled trial in Western Australia. Lancet, 388(10057), 2264-2271. https://doi.org/10.1016/S0140-6736(16)30384-1

Didion, J., \& Gatzke, H. (2004). The "baby think it over" experience to prevent teen pregnancy: A post-intervention evaluation. Public Health Nursing, 21(4), 331-337. https://doi.org/10.1111/j.0737-1209.2004.21406.x

Diez, V., \& Mistry, J. (2010). Early childbearing and educational attainment among mainland Puerto Rican teens. Journal of Adolescent Research, 25(5), 690-715. https://doi.org/10.1177/0743558410366592

Divine, J. H., \& Cobbs, G. (2001). The effects of infant simulators on early adolescents. Adolescence, 36(143), 593-600.

Elkind, D. (1967). Egocentrism in adolescence. Child Development, 38, 1025-1034. https://doi.org/10.2307/1127100

Herrman, J. W., Waterhouse, J. K., \& Chiquoine, J. (2011). Evaluation of an infant simulator intervention for teen pregnancy prevention. Journal of Obstetric, Gynecologic, \& Neonatal Nursing: Clinical Scholarship for the Care of Women, Childbearing Families, \& Newborns, 40(3), 322-328. https://doi.org/10.1111/j.1552-6909.2011.01248.x

Johannesson, E., Silén, C., Kvist, J., \& Hult., H.(2013). Students' experiences of learning manual clinical skills through simulation. Advances in Health Sciences Education, 18(1), 99-114. https://doi.org/10.1007/s10459-012-9358-z

Kolb, D. (1984). Experiential learning: Experiences as the source of learning and development. Upper Saddle River, NJ: Prentice-Hall.

Lou, J. H., \& Chen S. H. (2008). Relationships among sexual knowledge, sexual attitudes, and safe sex behavior among adolescents: A structural equation model. International Journal of Nursing Studies, 46, 1595-1603. https://doi.org/10.1016/j.ijnurstu.2009.05.017

Malinowski, A., \& Stamler, L. L. (2003). Adolescent girls' personal experience with baby think it over infant simulator. MCN. The American Journal of Maternal Child Nursing, 28(3), 205-211. 
Jang, L.-F., \& Lin, Y.-M.

https://doi.org/10.1097/00005721-200305000-00013

McCowan, R., Roberts, S. C., \& Slaughter, J. (2009). Using infant simulation to reduce pregnancy among high school students. The Healthy Educator, 41(1), 35-41.

Ministry of the Interior. (2013). Statistical reports on marital status on 2013. Retrieved from http://www.moi.gov.tw/stat/news_content.aspx?sn=7439

Mortimer, J. T., Zimmer-Gembeck, M. J., Holmes, M., \& Shanahan, M. J. (2002). The process of occupational decision making: Patterns during the transition to adulthood. Journal of Vocational Behavior, 61, 439-465. https://doi.org/10.1006/jvbe.2002.1885

Out, J. W., \& Lafreniere, K. D. (2001). Baby think it over: Using role-play to prevent teen pregnancy. Adolescence, 36(143), 571-582.

Price, J. H., Robinson. K. L., Thompson, C., \& Schmalzried, H. (2000). Rural parents' perceptions of the baby think it over program-A pilot study. American Journal of Health Studies, 16(1), 34-40.

Roberts, S. W., \& McCowan, R. J. (2004). The effectiveness of infant simulators. Adolescence, 39(155), 475-487.

Sauter, M., Uttal, D. H., Rapp, D. N., Downing, M., \& Jona, K. (2013). Getting real: The authenticity of remote labs and simulations for science learning. Distance Education, 34(1), 37-47. https://doi.org/10.1080/01587919.2013.770431

Somers, C. L., \& Fahlman, M. M. (2001), Effectiveness of the "baby think it over" teen pregnancy prevention program. Journal of School Health, 71, 188-195. https://doi.org/10.1111/j.1746-1561.2001.tb07314.x

Strachan, W., \& Gorey, K. M. (1997). Infant simulators lifespace in: Pilot investigation of an adolescent pregnancy prevention program. Child and Adolescent Social Work Journal, 14(3), 171-180. https://doi.org/10.1023/A:1024565502423

Tingle, L. R. (2002). Evaluation of the North Carolina "baby think it over" project. Journal of School Health, 72(5), 178-183. https://doi.org/10.1111/j.1746-1561.2002.tb06543.x 